\title{
Effect of maize internode lignification on in vitro cell-wall polysaccharide degradability
}

\author{
HG Jung 1, TA Morrison 2, DR Buxton 2 \\ USDA-Agricultural Research Service, US Dairy Forage Research Center Clusters, \\ 'St Paul, MN and ${ }^{2}$ Ames, IA, USA
}

\begin{abstract}
Lignin is considered the primary impediment to forage digestibility because of its negative impact on cell-wall breakdown. However, it has been shown that lignin concentration alone is a poor predictor of degradability within a forage species when samples are of similar maturity. Cross-linkage of lignin and polysaccharides in the cell wall by ferulic acid has been suggested to play a major role in explaining how lignification limits cell-wall degradability in grasses. But efforts to correlate the concentration of ferulate ethers with degradability have met with little success. Here we present data which supports the ferulate ether hypothesis and explains why it has not been possible to correlate their concentration with degradability in forages.
\end{abstract}

Maize plants were harvested at the 15th leaf stage of development and separated into individual internode segments. The rind from these stem internodes was analyzed for cellwall neutral sugars, uronics, Klason lignin, and ester- and ether-linked ferulic acid. Cell-wall polysaccharide degradability was determined for 24- and 96-h in vitro ruminal fermentations (Jung and Buxton, 1994, J Sci Fd Agric, 66, 313-322).

Lignin concentration increased from the youngest ( \#13, top of stem) to the oldest internode (\# 7, bottom of stem). Ferulate esters declined with internode maturity while ferulate ethers initially increased and then slowly declined in concentration with maturity. This change in ferulic acid linkage forms is consistent with the hypothesis that ferulate esters are laid down during primary wall growth and then become cross-linked with lignin via ether bonds during secondary wall thickening. Ferulate ethers decline in concentration with advanced maturity because no more ferulic acid is being deposited in the wall and dilution due to lignin accumulation is occurring. Cellwall polysaccharide degradability of both the rapidly ( $24 h$ ) and potentially (96h) degradable fractions declined from the youngest internode through \# 11, but then remained stable. Degradability declined sharply from internode \# 13 to \# 12 with a large increase in ferulate ethers, but only a small increase in lignin. A further decrease in degradability from internode \# 12 to \# 11 corresponded with a smaller increase in ferulate ethers and a large increase in lignin. While lignin continued to increase in older internodes, there was very little further change in degradability. Ferulate ethers were not correlated with degradability in these more mature internodes because of the lack of further ferulic acid deposition during lignin polymer deposition. Ferulate ethers are important determinants of cell-wall degradability in grasses, but their effect can only be observed in very immature tissues and is obscured with maturity.

\begin{tabular}{|c|c|c|c|c|c|}
\hline \multirow[b]{2}{*}{ Internode } & Klason & \multicolumn{2}{|c|}{ Ferulic acid } & \multicolumn{2}{|c|}{ Polysaccharide Degradation } \\
\hline & lignin & $\begin{array}{l}\text { Esters } \\
\mathrm{g} / \mathrm{kg} \mathrm{CW}\end{array}$ & Ethers & $24 \mathrm{~h}$ & $96 \mathrm{~h}$ \\
\hline 13 & $73^{a}$ & $5.99^{a}$ & $0.44^{\mathrm{a}}$ & $757^{a}$ & $894^{a}$ \\
\hline 12 & $78^{a}$ & $6.58^{\mathrm{a}}$ & $2.80^{\circ}$ & $675^{\circ}$ & $836^{b}$ \\
\hline 11 & $119^{b}$ & $4.99^{b}$ & $4.07^{b}$ & $529^{c}$ & $725^{c}$ \\
\hline 10 & $128^{b c}$ & $4.76^{b}$ & $3.75^{b}$ & $447^{d}$ & 676 cd \\
\hline 9 & $141^{\mathrm{bcd}}$ & $4.52^{\mathrm{bc}}$ & $3.25^{b}$ & $436^{d}$ & $699 \mathrm{~cd}$ \\
\hline 8 & 144 cd & $4.08^{\mathrm{bc}}$ & $3.72^{b}$ & $439^{d}$ & $667^{d}$ \\
\hline 7 & $159^{d}$ & $3.64 c$ & $3.18^{b}$ & $376^{d}$ & $654^{d}$ \\
\hline
\end{tabular}

a. b. c. d: Means in the same column not sharing a superscript are different $(P<0.10)$. 